OLIVEIRA, F.L.; RIBEIRO, R.L.D.; SILVA, V.V.; GUERRA, J.G.M.; ALMEIDA, D.L. Desempenho do inhame (taro) em plantio direto e no consórcio com crotalária, sob manejo orgânico. Horticultura Brasileira, Brasília, v.22, n.3, p.638-641, jul-set 2004.

\title{
Desempenho do inhame (taro) em plantio direto e no consórcio com crotalária, sob manejo orgânico
}

\author{
Fábio Luiz de Oliveira ${ }^{1}$; Raul de L.D. Ribeiro ${ }^{1}$; Vinícius V. Silva² ${ }^{2}$ José Guilherme M. Guerra ${ }^{3}$; Dejair L. \\ de Almeida ${ }^{3}$ \\ ${ }^{1}$ UFRRJ , BR 465, km 07, 23890-000 Seropédica-RJ; E-mail: fabiocapi@ ufrrj.br; ²Pesagro-Rio, Rodovia RJ 116, 23785-000 Rio de \\ Janeiro-RJ; ${ }^{3}$ Embrapa Agrobiologia, BR 465, km 07, C. Postal 74505, 23890-000 Seropédica-RJ; E-mail: gmguerra@ cnpab.embrapa.br
}

\section{RESUMO}

Estudaram-se os efeitos do plantio direto em cobertura morta de aveia-preta e do consórcio com Crotalaria juncea, em sistema orgânico de produção de inhame, em ensaio na EE de Nova Friburgo (Pesagro-Rio), região serrana do estado do Rio de Janeiro. Utilizouse o delineamento de blocos ao acaso com quatro repetições, em esquema fatorial $2 \times 2$, onde os tratamentos corresponderam ao: modo de plantio (direto ou convencional) e modo de cultivo (monocultivo ou consórcio com crotalária). O cultivo consorciado com a leguminosa promoveu maior altura nas plantas do inhame, assim como reduziu a queima de folhas pelos raios solares. A população infestante de ervas espontâneas foi mais efetivamente controlada com a combinação entre consórcio e plantio direto. Nenhum dos tratamentos influenciou a produtividade do inhame, que foi considerada satisfatória, indicando o potencial do manejo orgânico adotado.

Palavras-chave: Colocasia esculenta, aveia-preta, adubação verde, agroecologia.

\section{ABSTRACT}

Main development in direct planting and in conjunction with sun hemp under organic management

An experiment was carried out in the upland region of Rio de Janeiro State, Brazil, to evaluate different planting systems on yam performance under organic management. A randomized blocks design was used with four replications, in a $2 \times 2$ factorial scheme comprising the treatments: soil tillage system (no-tillage or conventional) and cropping system (monoculture or intercropping with Crotalaria juncea). Intercropping with $C$. juncea (sun hemp) stimulated yam vegetative growth and reduced leaf blight caused by sun radiation. The weed population was reduced more effectively associating notillage and intercropping with sun hemp. None of the treatments affected yam yield, which was considered satisfactory indicating the potential of the organic management adopted.

Keywords: Colocasia esculenta, black oat, green manuring, agroecology.

(Recebido para publicação em 24 de agosto de 2003 e aceito em 5 de maio de 2004)

$\mathrm{O}$ sistema de plantio direto vem sendo com frequiência utilizado em lavouras destinadas à produção de grãos que se caracterizam pelo elevado aporte de insumos industriais (fertilizantes minerais e agrotóxicos, especialmente herbicidas). Esses insumos não são admitidos na produção orgânica. Desse modo, são necessários esforços para o desenvolvimento de sistemas alternativos, sobretudo viáveis para o pequeno agricultor, havendo, atualmente, maior demanda para culturas de hortaliças (Merten, 1983; Ribeiro et al., 1993). No caso específico do inhame (Colocasia esculenta), destaca-se a necessidade da geração de tecnologias apropriadas, levando-se em consideração aspectos como adubação verde, cobertura morta, controle da vegetação espontânea e crestamento foliar pela incidência direta de raios solares (Nolasco, 1994).

No que diz respeito à adubação verde, diversos autores relataram seus benefícios ligados à biota no sistema solo- planta (Miyasaka et al., 1966; Araujo e Almeida, 1993; De-Polli et al., 1996; Oliveira, 2001). Apesar de as gramíneas serem muito usadas, as leguminosas são as preferidas para adubação verde, por sua alta capacidade de fixar nitrogênio atmosférico, significando uma alternativa de se fornecer esse nutriente às plantas, o que contribui expressivamente na redução dos custos de produção de culturas econômicas. Além disso, as leguminosas têm considerável potencial de produção de biomassa rica em nutrientes e capaz de manter ou aumentar o teor de matéria orgânica do solo (Franco e Souto, 1984).

O objetivo do presente trabalho foi determinar os efeitos da aveia-preta (Avena strigosa) e da crotalária (Crotalária juncea) em sistemas de plantio direto e cultivo consorciado, respectivamente, no desempenho da cultura do inhame (taro), submetida a manejo orgânico, na região serrana do estado do Rio de Janeiro.

\section{MATERIAL E MÉTODOS}

O experimento foi instalado em 2001, na EE de Nova Friburgo (PesagroRio), região serrana do estado do Rio de Janeiro. Utilizou-se delineamento de blocos ao acaso com quatro repetições, em esquema fatorial $2 \times 2$, em que os tratamentos corresponderam ao: modo de plantio (direto ou convencional) e modo de cultivo (monocultivo ou consórcio com $C$. juncea). A aveia-preta foi semeada no mês de maio, como adubo verde de pré-cultivo, sendo cortada em agosto, ocasião em que foi plantado o inhame, que foi colhido no final de abril de 2002, reiniciando-se o ciclo com a aveia-preta.

As parcelas comportaram 32 plantas de inhame, no espaçamento de $1,0 \mathrm{x}$ $0,5 \mathrm{~m}$, dispostas em quatro linhas de plantio, sendo considerada como área útil aquela ocupada por 12 plantas das linhas interiores de cada parcela. 
A análise química do solo, coletado à profundidade de $0-20 \mathrm{~cm}$, apresentou: $\mathrm{pH}$ em água $=5,3, \mathrm{Al}^{+3}=0,1 \mathrm{cmol} / \mathrm{dm}^{3}$, $\mathrm{Ca}^{+2}=3,6 \mathrm{cmol} / \mathrm{dm}^{3}, \mathrm{Mg}^{+2}=1,3 \mathrm{cmol}_{\mathrm{c}} /$ $\mathrm{dm}^{3}, \mathrm{~K}^{+}=227 \mathrm{mg} / \mathrm{kg}$ e $\mathrm{P}=199 \mathrm{mg} / \mathrm{kg}$ ).

A cultivar de inhame usada no experimento representa um ecotipo preferido pelos produtores da região, apresentando rizomas com túnica roxa e polpa branca. Apesar da existência de uma sinonímia muito grande com relação ao material genético plantado no Rio de Janeiro, acredita-se que pertença ao grupo denominado "Chinês", bem adaptado às diversas regiões produtoras do Estado e de boa aceitação comercial.

A aveia-preta foi semeada a lanço e roçada rente ao solo quando se apresentava em estádio de plena floração, aos 120 dias após semeadura, sendo logo em seguida incorporada, com enxada rotativa, nas parcelas de manejo convencional. A crotalária foi semeada na densidade de 20 sementes por metro linear, em fileiras duplas espaçadas de $0,50 \mathrm{~m}$, nas entrelinhas do inhame, 60 dias após o plantio deste, por ocasião da primeira capina e mantida permanentemente em consórcio.

Foram feitas avaliações da ocorrência natural de ervas espontâneas, determinando-se biomassa total, além de algumas características fitotécnicas do inhame: área foliar, altura da planta, número de folhas por planta, conteúdo de nitrogênio total nas folhas, conforme Alves et al. (1994), peso médio do rizoma central, peso médio dos rebentos, número de rebentos por planta, produtividade e incidência de queimadura solar nas folhas, estimada por meio da escala diagramática de Micherreff et al. (2000), modificada.

\section{RESULTADOS E DISCUSSÃO}

Na análise da variância, o teste "F" não indicou interação entre cultivo consorciado com crotalária e plantio direto na palha de aveia-preta, em relação à altura da planta, área foliar e número de folhas por planta. Por outro lado, houve interação com respeito ao teor de nitrogênio nas folhas do inhame.

A altura da planta foi aumentada no consórcio com crotalária, em relação ao monocultivo, enquanto que a área foliar

Tabela 1. Altura das plantas, área foliar e número de folhas por planta de inhame, no sexto mês, em monocultivo ou consorciado com C. juncea, a partir de plantio direto na palha de aveia-preta e de plantio convencional, submetido a manejo orgânico. Nova Friburgo, UFRRJ/ Embrapa Agrobiologia, 2002.

\begin{tabular}{lccc}
\hline Sistema de cultivo & $\begin{array}{c}\text { Altura da planta } \\
\text { (cm) }\end{array}$ & Área foliar $\left(\mathbf{c m}^{2}\right)$ & $\begin{array}{c}\text { Número de } \\
\text { folhas/planta }\end{array}$ \\
\hline Consorciado & $86,21 \mathrm{a}^{1}$ & $2246,76 \mathrm{a}$ & $5,10 \mathrm{a}$ \\
Monocultivo & $65,95 \mathrm{~b}$ & $2843,40 \mathrm{a}$ & $5,17 \mathrm{a}$ \\
Plantio direto & $72,80 \mathrm{a}^{1}$ & $2440,56 \mathrm{a}$ & $5,24 \mathrm{a}$ \\
Plantio convencional & $79,36 \mathrm{a}$ & $2649,56 \mathrm{a}$ & $5,02 \mathrm{a}$ \\
\hline
\end{tabular}

\begin{tabular}{llll}
\hline $\mathrm{CV}(\%)$ & 12 & 28 & 3
\end{tabular}

${ }^{1}$ Médias seguidas da mesma letra, nas colunas, não diferem entre si pelo teste $F(p<0,05)$. Nova Friburgo, UFRRJ, 2002.

Tabela 2. Efeito do consórcio com $C$. juncea sobre o número de folhas por planta afetadas por queimadura solar, área da folha índice afetada, e incidência de queimadura nas plantas de inhame submetida a manejo orgânico, cinco e oito meses após o plantio. Nova Friburgo, UFRRJ/EmbrapaAgrobiologia, 2002.

\begin{tabular}{|c|c|c|c|c|c|c|}
\hline \multirow[t]{2}{*}{$\begin{array}{l}\text { Sistema de } \\
\text { cultivo }\end{array}$} & \multicolumn{2}{|c|}{$\begin{array}{l}\text { Número de } \\
\text { folhas/planta }\end{array}$} & \multicolumn{2}{|c|}{$\begin{array}{l}\text { Área da folha índice } \\
\qquad\left(\mathrm{cm}^{2}\right)\end{array}$} & \multicolumn{2}{|c|}{$\begin{array}{c}\text { Plantas com } \\
\text { queimaduras foliares } \\
(\%)\end{array}$} \\
\hline & $5^{\circ}$ mês & $8^{\circ}$ mês & $5^{\circ}$ mês & $8^{\circ}$ mês & $5^{\circ}$ mês & $8^{\circ}$ mês \\
\hline Consórcio & $0,00 b^{1}$ & $2,12 b$ & $0,00 \mathrm{~b}$ & $54,30 \mathrm{~b}$ & $0,00 \mathrm{~b}$ & $80 \mathrm{~b}$ \\
\hline Monocultivo & 1,75 a & $4,00 \mathrm{a}$ & 16,83 a & 129,46 a & $21,25 \mathrm{a}$ & $100 \mathrm{a}$ \\
\hline$\overline{C V}(\%)$ & 43 & 34 & 40 & 42 & 38 & 39 \\
\hline
\end{tabular}

${ }^{1}$ Médias seguidas da mesma letra, nas colunas, não diferem entre si pelo teste $F(p<0,05)$. Nova Friburgo, UFRRJ, 2002.

e o número de folhas por planta não sofreram influência do consórcio ou forma de preparo do solo (Tabela 1). O crescimento acentuado da crotalária, atingindo altura média de $1,80 \mathrm{~m}$, ocasionou sombreamento progressivo das plantas de inhame. Apesar de que, na família Arácea, a maioria das espécies é considerada como de sombra (Rubatzky e Yamaguchi, 1997), o cultivo do inhame consorciado com a crotalária promoveu alongamento dos pecíolos, o que elevou o porte das plantas, em comparação ao cultivo "solteiro", característica essa que normalmente não aparece em plantas consideradas de sombra (Taiz e Zeiger, 1998).

O plantio direto do inhame na palha de aveia-preta não influenciou altura, área foliar e número de folhas, quando comparado com o plantio convencional (Tabela 1). No cultivo consorciado com crotalária, independentemente do sistema de plantio, as plantas de inhame apresentaram teores de nitrogênio nas folhas $(4,61 \%$ com o plantio direto e $4,53 \%$ com o plantio convencional) significativamente superiores aos encontrados no monocultivo $(4,09 \%$ com o plan- tio direto e $3,69 \%$ com o plantio convencional). Dentro do sistema de monocultivo, as plantas cultivadas em plantio direto apresentaram teores de nitrogênio significativamente superiores que o sistema convencional.

Os resultados evidenciaram as vantagens proporcionadas pelo cultivo consorciado com leguminosas, principalmente no que diz respeito ao aporte de nitrogênio ao sistema e à ciclagem de nutrientes, reforçando os resultados obtidos por Yamoah et al. (1986), Kass et al. (1989), Kang et al. (1990), e Alves (2000). Além das vantagens do sistema de plantio direto, registradas por vários autores (Sidiras e Pavan, 1985; Bragagnolo e Mielniczuk, 1990; Sá, 1993a; Holtz, 1995), inclui-se a disponibilidade do $\mathrm{N}$ para pronta utilização pela cultura econômica, decorrente da decomposição da biomassa do pré-cultivo, deixada na superfície do solo.

O cultivo da crotalária em consórcio com o inhame promoveu sombreamento, diminuindo significativamente a intensidade dessas queimaduras. Até o quinto mês do ciclo da cultura, a redução foi de $100 \%$, enquanto 


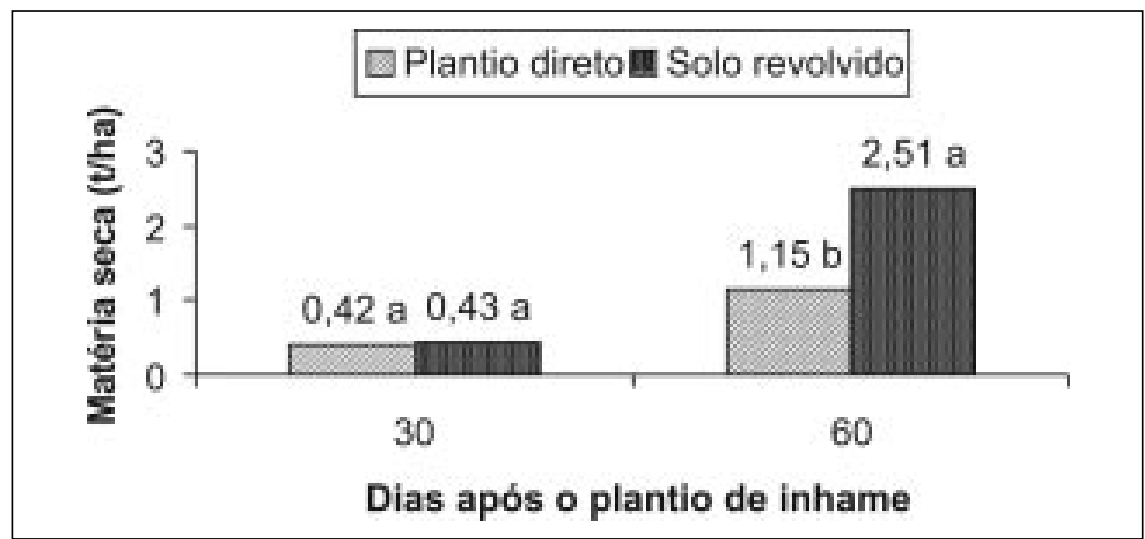

Figura 1. Biomassa da vegetação espontânea em cultivo de inhame, a partir de plantio direto na palha de aveia-preta e do plantio convencional após incorporação com enxada rotativa. Nova Friburgo UFRRJ, 2002.

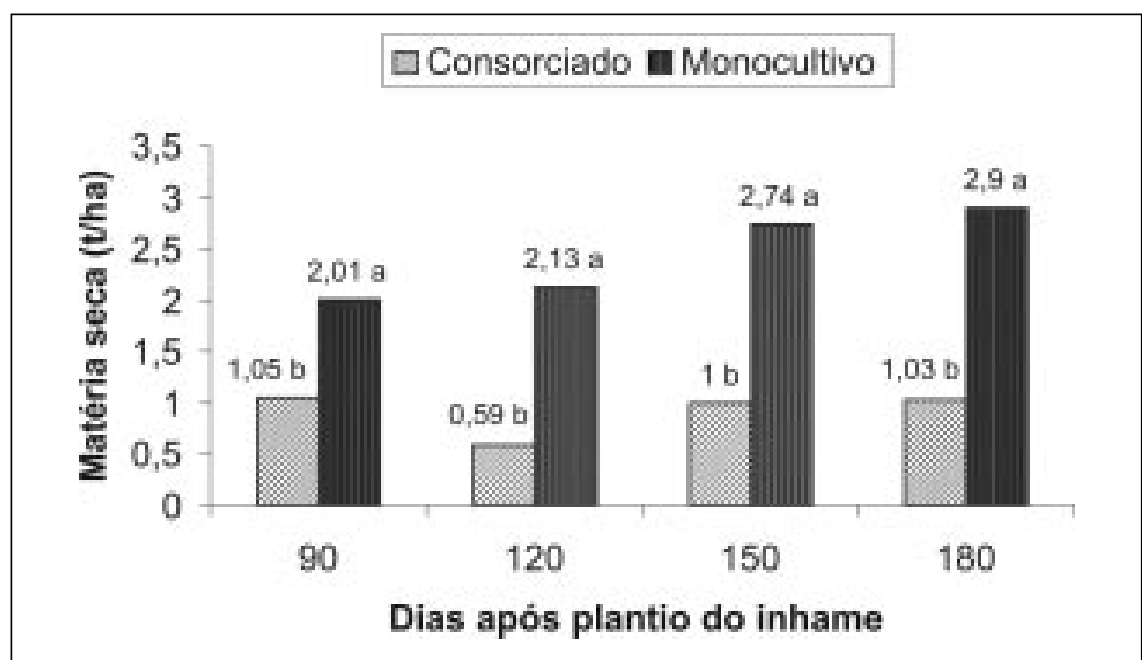

Figura 2: Biomassa da vegetação espontânea em monocultivo inhame e no cultivo consorciado com Crotalaria juncea. Nova Friburgo UFRRJ, 2002).

no oitavo mês o sombreamento continuava protegendo as plantas, porém com um grau de eficiência menor (Tabela 2). Deve-se, porém, ressaltar que nessa época a cultura do inhame já estava completando seu ciclo, ocasião em que o desfolhamento poderia trazer algum beneficio, acelerando a maturação das plantas e o carreamento de nutrientes da parte aérea para os órgãos de reserva. No caso do inhame, este acúmulo de nutrientes poderia, assim, significar ganho de peso dos rizomas a comercializar, melhorando o rendimento da cultura. De acordo com o levantamento realizado pela RECOPE-RJ (Rede de Agroecologia do estado do Rio de Janeiro), em seu relatório do $2^{\circ}$ semestre de 1999, os plantios do inhame no estado do Rio de Janeiro sofrem, quase sem- pre, com queimaduras foliares extensas, em função da incidência direta dos raios solares. As lesões provocadas levam à perda de área foliar e, por conseqüência, à diminuição na produção de fotoassimilados, podendo afetar negativamente o desenvolvimento dos rizomas.

O sistema de cultivo em consórcio com a crotalária, associado ao plantio direto na palha de aveia-preta revelouse uma alternativa eficaz para controle da vegetação espontânea, prescindindose das capinas e do uso de herbicidas. Até 60 dias do plantio do inhame, a cobertura do solo com a palha da aveiapreta diminuiu a reinfestação pela vegetação espontânea, que era composta, predominantemente, por losna-brava (Artemisia verlotorum), botão-de-ouro
(Siegesbeckia orientalis) e picão-preto (Bidens pilosa $\mathrm{L}$.) representando cerca de $90 \%$ das plantas coletadas, mantendo-a em níveis aceitáveis (Figura 1). Resultados similares foram obtidos por Okugie e Ossom (1988), que reportaram o controle da vegetação espontânea com o uso de cobertura morta (mulch) de capim colonião (Panicum maximum) e por Yih (1989) que observou efeito supressivos sobre reinfestação da vegetação espontânea, com o uso de "mulch" de gramíneas, no cultivo da batata-doce.

As capinas oneram o custo de produção do inhame, cujo ciclo é longo, mas são necessárias para o controle da vegetação espontânea, que acarreta prejuízos ao rendimento da cultura, competindo por água e nutrientes (Plucknett et al., 1970; Onwueme, 1978; Pimenta, 1993). Assim, o emprego conjunto do plantio direto e do cultivo consorciado torna-se importante, pois quando o "mulch" de aveia-preta começa a perder sua capacidade de supressão sobre a vegetação espontânea, intensifica-se a ação da crotalária (Figura 2), predominando na competição por luz, água e nutrientes e exercendo a supressão sobre a vegetação espontânea, otimizando os custos com capinas.

$\mathrm{O}$ plantio direto não influenciou os componentes de rendimento da cultura do inhame, não alterando a produtividade (plantio direto 9,15 t/ha; convencional $8,82 \mathrm{t} / \mathrm{ha}$ ). Entretanto, com o tempo, os benefícios quanto as características físicas, químicas e biológicas do solo teriam, provavelmente, reflexos positivos na produtividade do inhame. O mesmo caberia colocar em relação ao consórcio com a crotalária, que, embora tendo proporcionado controle da queima de folhas pelo sol e da população de ervas espontâneas, não influiu, a curto prazo na capacidade produtiva do inhame (consorciado 8,96 t/ha; monocultivo 9,01 t/ha). Cabe ressaltar que a lavoura sofreu a ação de um severo veranico no mês de janeiro, correspondente ao quinto mês de ciclo da cultura, que coincide com um período de formação dos órgãos de reserva da planta, o que refletiu em uma produtividade, em todos os tratamentos, abaixo do normalmente encontrado para região.

Dessa forma pode-se concluir que o cultivo consorciado com C. juncea pro- 
moveu maior altura nas plantas do inhame, além de ter controlado a queimadura de folhas pelo sol e a reinfestação pela vegetação espontânea. A associação entre o consórcio com a leguminosa e o plantio direto na palhada de pré-cultivo de aveia-preta reduziu a população de ervas espontâneas. Os diferentes sistemas de produção não tiveram influência na produtividade do inhame, mas o manejo orgânico adotado proporcionou rendimento satisfatório.

\section{AGRADECIMENTOS}

À CAPES pela concessão da bolsa de doutorado, à FAPERJ pelo auxílio financeiro concedido para realização deste trabalho e à PESAGRO-RIO pela disponibilização da EE de Nova Friburgo (RJ).

\section{LITERATURA CITADA}

ALVES, B.J.R.; SANTOS, J.C.F.; URQUIAGA, S.; BODDEY, R.M. Métodos de determinação de nitrogênio em tecidos de plantas. In: HUNGRIA, M.; ARAUJO, R.S. (Eds). Manual de métodos empregados em estudos de microbiologia agrícola. Londrina/PR: Embrapa - CNPAF, 1994. 542 p.

ALVES, S.M.C. Produção orgânica de algumas hortaliças sob sistema de cultivo em aléias de guandu (Cajanus cajan). 2000. 114 p. (Tese mestrado). UFRRJ, Seropédica.

ARAÚJO, A.P.; ALMEIDA, D.L. Efeitos da adubação verde associada à adubação com fosfato natural na cultura do milho. Pesquisa Agropecuária Brasileira, Brasília, v.28, n.2, p.245251, 1993.

BRAGAGNOLO, N.; MIELNICZUK, J. Cobertura do solo por resíduos de oito sequiências de culturas e seu relacionamento com a temperatura e umidade do solo, germinação e crescimento inicial do milho. Revista Brasileira de Ciência do Solo, Campinas, v.14, p.91-98, 1990a.
DE-POLLI, H., GUERRA, J.G.M.; ALMEIDA, D.L.; FRANCO, A.A. Adução verde: parâmetros para avaliação de sua eficiência. In: CASTRO FILHO, C. \& MUZILLI, O. (eds.) Manejo integrado de solos em microbacias hidrográficas. Londrina, IAPAR/SBCS, 1996, p.225-242.

FRANCO, A.A.; SOUTO, S.M. Contribuição da fixação biológica de $\mathrm{N}_{2}$ na adubação verde. In; Adubação Verde no Brasil, Fundação Cargil, Campinas, p.199-215, 1984

HOLTZ, G.P., Dinâmica da decomposição da Palhada e da Distribuição do Carbono, Nitrogê nio e Fósforo numa Rotação de Culturas Sob Plantio Direto na Região de Carambeí-PR. 1995. 129 p. (Tese mestrado) UFPR. Curitiba.

KANG, B.T.; REYNOLDS, L.; ATTA-KRAH, A.N. Alley farming. Advances in Agronomy, Madison, v.43, p.315-359, 1990.

KASS, D.; BARRANTES, W.; CAMPOS, W.; JIMÉNEZ, M.; SÁNCHEZ, J. Resultados de seis años de investigation de cultivo en callejones (alley cropping), en "La Montaña”, Turrialba, n.19, p.524, 1989.

MERTEN, G.H., Desafio do Plantio Direto em Solos de Baixa Aptidão Agrícola, In: FUNDAÇÃO ABC, CURSO INTENSIVO SOBRE PLANTIO DIRETO NA PALHA, 1983, Castro. Resumos..., Castro: FUNDAÇÃO ABC, 1983. p.126.

MICHERREFF, S.J.; MAFFIA, L.A.; NORONHA, M.A. Escala diagramática para avaliação da severidade da queima das folhas do inhame. Fitopatologia Brasileira, Brasília, v.25, n.4, p.612-619, 2000.

MIYASAKA, S.; FREIRE, E.S.; MASCARENHAS, H.A.A.; NERY, C.; CAMPANA, M.; SORDI, G. Efeito da adubação verde com uma gramínea e quatro leguminosas sobre a produção do feijoeiro da seca, em terra roxa misturada. Bragantia, Campinas, v.25, p.349363, 1966.

NOLASCO, F. Necessidades e prioridades da pesquisa para a cultura do inhame (Colocasia esculenta). In: CORREA, L.G. (Coords). I ${ }^{\circ} \mathrm{EN}$ CONTRO NACIONAL SOBRE A CULTURA DO INHAME (Colocasia esculenta), 1994, Viçosa, Anais..., Viçosa: UFV, 1994, p.55-57.

OKUGIE, D.N.; OSSOM, E.M. Effect of mulch on the yield, nutrient concentration and weed infestation of the flued pumpkin (Telfairia occidentalis). Tropical Agriculture., v.65, p.202204, 1988.
OLIVEIRA, F.L. Manejo orgânico da cultura do repolho (Brassica oleracea var. capitata): adubação orgânica, adubação verde e consorciação. 2001. 87 p. (Tese mestrado), UFRRJ, Seropédica. ONWUEME, I.C. The tropical tuber crops: Yams, Cassava, Sweet Potato and Cocoyams. Great Britain, Pitman Press, 1978, 234 p.

PARRIS, G.K. Diseases of taro in Hawaii and their control. s.1., 1941. 29 p. (Hawaii Agric. Exp. Stn. Cienc. 18)

PIMENTA, D.S. Crescimento e produção de inhame (Colocasia esculenta), com composto orgânico, amontoa e capina. 1993. 78 p. (Tese mestrado), UFV, Viçosa.

PLUCKNETT, D.L.; DE LA PEÑA, R.S.; OBRERO, F. Taro (Colocasia esculenta). Field Crops Abstracts, v.23, n.4, p.413-423, 1970.

RECOPE-RJ (Rede de Agroecologia do Estado do Rio de Janeiro), Relatório trimestral, Embrapa Agrobiologia, Seropédica/RJ, julho a setembro de 1999.

RIBEIRO, M.F.S.; MERTEN, G.H.; SKORA NETO, F. Plantio na Palha na Pequena Propriedade, In: EMBRAPACNPT£FECOTRIGO£FUNDAÇÃO ABC, Plantio Direto no Brasil, Passo Fundo, Aldeia Norte, 1993. p.151-158.

RUBATZKY, V.E.; YAMAGUCHI, M. World vegetables. Principles, production and nutritive value. 2 ed. New York : Chapman \& Hall, 1997. 843 p.

SÁ, J.C.M. Manejo da Fertilidade do Solo no Sistema de Plantio Direto, In: EMBRAPACNPT£FECOTRIGO£FUNDAÇÃO ABC, Plantio Direto no Brasil Passo Fundo, Aldeia Norte, 1993. p.37-60.

SIRIDAS, N.; PAVAN, M.A. Influencia dos sistemas de manejo do solo no seu nível de fertilidade. Revista Brasileira de Ciências do Solo, Campinas, v.9, p.249-254, 1985.

TAIZ, L.; ZEIGER, E. Phytochrome. In: TAIZ, L.; ZEIGER, E. Plant physiology. Sinauer Associates, Inc., Publishers Sunderland, Massachusetts, USA. $2^{\circ}$ edição, 1998. p. $483-516$.

YAMOAH, C.F.; AGBOOLA, A.A.; WILSON, G.F. Nutrient contribuition and maize perfomance in alley cropping. Agroforestry Systems, v.4, p.239246, 1986.

YIH, W.K. The effects of plant litter and inorganic fertilizers on crop-weed interation in a temperate rich-soil site. Biol. Agric. Hort. V.6, n.1, p.59-72, 1989. 